\title{
Personalizing the alcohol-IAT with individualized stimuli: relationship with drinking behavior and drinking-related problems
}

Citation for published version (APA):

Houben, K. M. P. I., \& Wiers, R. W. H. J. (2007). Personalizing the alcohol-IAT with individualized stimuli: relationship with drinking behavior and drinking-related problems. Addictive Behaviors, 32, 2852-2864. https://doi.org/10.1016/j.addbeh.2007.04.022

Document status and date:

Published: 01/01/2007

DOI:

10.1016/j.addbeh.2007.04.022

Document Version:

Publisher's PDF, also known as Version of record

Document license:

Taverne

Please check the document version of this publication:

- A submitted manuscript is the version of the article upon submission and before peer-review. There can be important differences between the submitted version and the official published version of record.

People interested in the research are advised to contact the author for the final version of the publication, or visit the DOI to the publisher's website.

- The final author version and the galley proof are versions of the publication after peer review.

- The final published version features the final layout of the paper including the volume, issue and page numbers.

Link to publication

\footnotetext{
General rights rights.

- You may freely distribute the URL identifying the publication in the public portal. please follow below link for the End User Agreement:

www.umlib.nl/taverne-license

Take down policy

If you believe that this document breaches copyright please contact us at:

repository@maastrichtuniversity.nl

providing details and we will investigate your claim.
}

Copyright and moral rights for the publications made accessible in the public portal are retained by the authors and/or other copyright owners and it is a condition of accessing publications that users recognise and abide by the legal requirements associated with these

- Users may download and print one copy of any publication from the public portal for the purpose of private study or research.

- You may not further distribute the material or use it for any profit-making activity or commercial gain

If the publication is distributed under the terms of Article 25fa of the Dutch Copyright Act, indicated by the "Taverne" license above, 


\title{
Personalizing the alcohol-IAT with individualized stimuli: Relationship with drinking behavior and drinking-related problems
}

\author{
Katrijn Houben $^{\mathrm{a}, *}$, Reinout W. Wiers ${ }^{\mathrm{a}, \mathrm{b}, \mathrm{c}}$ \\ ${ }^{a}$ Faculty of Psychology, Department of Experimental Psychology, Maastricht University, Maastricht, The Netherlands \\ ${ }^{\mathrm{b}}$ Behavioural Science Institute, Radboud University Nijmegen, Nijmegen, The Netherlands \\ ${ }^{\mathrm{c}}$ IVO, Addiction Research Institute, Rotterdam, The Netherlands
}

\begin{abstract}
Research aimed at uncovering implicit cognitive processes involved in alcohol use and abuse has demonstrated that implicit attitudes toward alcohol are negative and unrelated to drinking behavior. Here, it was examined whether these findings could be due to contamination of the IAT by extrapersonal associations that are irrelevant to behavior. Participants performed a traditional alcohol-IAT as well as a personalized IAT, which has been demonstrated to reduce extrapersonal contamination. Additionally, the personalized IAT presented individualized stimuli, which should further reduce extrapersonal contamination. Consistent with this hypothesis, significantly weaker IAT effects emerged in the personalized IAT compared to the traditional IAT. However, both the traditional and personalized IAT still indicated negative implicit attitudes toward alcohol. Incremental predictive validity was demonstrated for both tasks. Importantly, these findings underscore the importance of implicit attitudes toward alcohol as determinants of alcohol use and abuse.
\end{abstract}

(C) 2007 Elsevier Ltd. All rights reserved.

Keywords: Alcohol; Implicit cognition; Implicit Association Test; Personalized IAT; Individualized stimuli

\section{Introduction}

Contemporary dual process models state that addictive behaviors are determined by the dynamic interplay of two qualitatively different cognitive processes: fast, associative, automatic or implicit

\footnotetext{
* Corresponding author. Experimental Psychology, Maastricht University, PO BOX 616, 6200 MD Maastricht, The Netherlands. Tel.: +31 433881953; fax: +31 433884196 .

E-mail address: K.Houben@psychology.unimaas.nl (K. Houben).
} 
cognitive processes and slow, deliberative, controlled or explicit cognitive processes (e.g., Deutsch \& Strack, 2006; Evans \& Coventry, 2006; see also Wiers \& Stacy, 2006a,b). Further, it has been suggested that automatic cognitive processes become increasingly important as excessive substance use develops into an addiction (e.g., Bechara, Noel, \& Crone, 2006; Deutsch \& Strack, 2006; Evans \& Coventry, 2006). Whereas self-report measures can be easily used to tap controlled cognitive processes, it is far more difficult to measure automatic cognitive processes since participants may not always be able to report on the automatic cognitive processes underlying their behavior. Therefore, researchers have recently started using indirect measures of alcohol-related cognitions, which are more resistant to self-presentation biases than self-report measures because they infer cognitive processes indirectly from performance on a speeded reaction-time task. Hence, indirect measures could be uniquely suited to tap automatic cognitive processes while at the same time limiting participants' ability for controlled responding. As such, indirect measures could lead to important new insights in the study of alcohol-related cognitions involved in alcohol use and abuse.

In order to reveal implicit cognitions that influence alcohol use and abuse, Wiers, Van Woerden, Smulders, and de Jong (2002) used the Implicit Association Test (IAT, Greenwald, McGhee, \& Schwartz, 1998) as an indirect measure of implicit alcohol-related cognitions in light and heavy drinkers. In the IAT, the participants' task is to quickly and accurately classify stimuli into two target categories and two attribute categories using two response keys. The underlying logic is that classification performance should be better when associated target concepts and attribute categories share a response (i.e., compatible response assignment) than when target categories are paired with unassociated attribute categories (i.e., incompatible response assignment). Using the IAT, Wiers et al. (2002) found that both light and heavy drinkers were faster when alcohol and negative attributes were assigned to the same response, and soda and positive attributes to the other response than when alcohol shared a response with positive attributes and soda with negative attributes. Hence, these results indicate that both light and heavy drinkers had negative implicit attitudes toward alcohol. Wiers et al. (2002) did find a differentiation between light and heavy drinkers with a second IAT: Heavy drinkers were faster when alcohol shared a response with arousal and soda with sedation, than when alcohol and sedation were assigned to one response and soda and arousal to the other. This effect, however, was absent in light drinkers. Wiers et al. (2002) hypothesized that these results were in line with the incentive-sensitization theory of Robinson and Berridge (1993) according to which addictive behaviors such as alcohol use are related more to "wanting" (i.e., sensitized arousal) the addictive substance than to "liking" of the substance. These results were also replicated in a sample of heavy drinkers (Wiers, van de Luitgaarden, van den Wildenberg, \& Smulders, 2005) as well as in a sample of patients undergoing treatment (De Houwer, Crombez, Koster, \& De Beul, 2004). Further, Palfai and Ostafin (2003) showed that that alcohol is associated with implicit approach motivations (or action tendencies) in hazardous drinkers. Importantly, stronger implicit alcohol-approach associations significantly correlated with urge to drink and arousal-reactivity in anticipation of alcohol consumption. Together, these results suggest that drinking behavior is primarily determined by implicit "wanting" or implicit appetitive associations with alcohol (e.g., implicit arousal associations and implicit approach tendencies) whereas implicit attitudes toward alcohol do not appear to be involved in drinking behavior.

It is, however, possible that results with the alcohol-IAT do not reflect implicit negative attitudes toward alcohol but instead culturally shared associative knowledge about drinking alcohol and its negative consequences, which does not influence behavior. In line with such a conclusion, it was demonstrated that the IAT is sensitive to so-called extrapersonal associations that do not form the basis of 
one's attitudes and that are irrelevant to behavior. Such extrapersonal associations may stem from cultural norms (Karpinski \& Hilton, 2001) or from other sources of information, such as the media and other people (Olson \& Fazio, 2004). Although such extrapersonal associations may affect IAT performance, they need to be distinguished from personal associations that, unlike extrapersonal associations, are automatically activated and guide behavior (Olson \& Fazio, 2004). Olson and Fazio (2004) argue that contamination of the IAT by extrapersonal associations is promoted due to normative implications of the attribute labels 'positive' and 'negative' as well as the use of normatively positive and negative attribute exemplars. In addition, giving error feedback in the IAT also suggests that there is a normatively correct answer. Therefore, they developed the personalized IAT, which reduces contamination by extrapersonal associations because all references to normative information are eliminated: The labels 'positive' and 'negative' are replaced with the labels 'I like' and 'I dislike', stimuli are used that are not normatively associated with valence but that have little evaluative consensus (e.g., football, coffee), and no error feedback is presented. Houben and Wiers (in press) recently examined implicit attitudes toward alcohol with a personalized IAT as developed by Olson and Fazio (2004). In line with the hypothesis that previous results with the standard alcohol-IAT may to some extent reflect negative extrapersonal associations with alcohol, the personalized IAT revealed support for implicit positive attitudes toward alcohol. Further, stronger positive implicit attitudes toward alcohol were related to an increase in alcohol intake. Thus, these results suggest a reduced influence of extrapersonal associations with alcohol in the personalized IAT and indicate that positive implicit attitudes toward alcohol play a role in drinking behavior.

However, as has also been pointed out by Fadardi, Cox, and Klinger (2006), the personalized IAT presents stimulus words for which there is no evaluative consensus, but these stimuli are nevertheless the same for all participants. It is questionable how well an IAT that presents standard stimuli can capture participants' personal associations, since standard stimuli will probably differ in the degree to which they are both known and liked across participants. This is particularly true when applied to alcohol research since there is probably great variation in the alcoholic drinks that are known and liked by participants. In line with this idea, Houben and Wiers (submitted for publication-b) have demonstrated that implicit attitudes toward beer, in contrast to more general implicit attitudes toward alcohol, were related to alcohol consumption in a sample of participants who drank beer on a regular basis. Hence, it might be useful to personalize the IAT, not only by removing all reference to normative information, but also by using individualized words (e.g., participants' favorite drinks). This possibility was examined in the present study. Participants' scores on a standard alcohol-IAT, similar to those used in previous studies, were compared to their scores on a personalized IAT that presented stimuli that were individualized for each participant. More specifically, each participant reported his or her favorite alcoholic drinks and sodas, which were then used as the stimuli for the target categories in the personalized IAT that was performed by that participant. The target categories were labeled 'my drink' and 'my soda', respectively. Further, all participants also listed positive and negative words that were subsequently used as the stimuli for the attribute categories 'I like' and 'I dislike', respectively. Finally, no error feedback was presented during the personalized IAT. It was expected that the standard IAT would show support for implicit negative attitudes toward alcohol, replicating previous findings. In contrast, it was expected that the personalized IAT would yield evidence for implicit positive attitudes toward alcohol. Importantly, it was expected that the personalized IAT would show a stronger relation to self-reported alcohol use and alcohol-related problems compared to the standard IAT, suggesting a reduced contamination by extrapersonal associations in the personalized IAT. 


\section{Method}

\subsection{Participants}

Forty-six students of Maastricht University (31 females, 15 males; mean age $=21.33$ years, $\mathrm{SD}=1.84$ ) voluntarily participated in exchange for a gift certificate. Average alcohol consumption per week was $15.63\left(\mathrm{SD}=14.49\right.$; range $=0-65.5$ glasses of alcohol per week) Dutch standard drinks. ${ }^{1}$ On the 18 -items version of the Rutgers Alcohol Problem Index (RAPI; White \& Labouvie, 2000), participants' mean item score was $.51(\mathrm{SD}=.38$; range $=0-1.78)$, while the average item score in clinical samples is about .80 (White \& Labouvie, 1989). On the Alcohol Use Disorder Identification Test (AUDIT; Saunders, Aasland, Babor, De la Fuente, \& Grant, 1993), participants' mean score was 11.11 (SD=5.38; range=1-25), while the proposed AUDIT cut-off score for the screening of alcohol-related problems is 11 (Saunders et al., 1993).

\subsection{Materials and measures}

\subsubsection{Alcohol use}

Alcohol use was measured with a self-report questionnaire (Wiers, Hoogeveen, Sergeant, \& Gunning, 1997) based on the timeline follow-back method (Sobell \& Sobell, 1990). Participants were asked to indicate how many drinks of different types of alcoholic beverages they consumed during each day of the past week, and how many drinks they typically consumed on each day of the week.

\subsubsection{Alcohol-related problems}

Alcohol-related problems were assessed with the RAPI and with the AUDIT. The RAPI described 18 alcohol-related problems or situations for which participants indicated how often they experienced these situations on a 5 -point Likert scale $(0=$ never, $4=$ very often) (Cronbach's $\alpha=.82)$. The AUDIT consisted of 10 questions $(\alpha=.85)$, of which the first three were related to alcohol use, and the other seven to alcohol-related problems.

\subsubsection{Implicit association test}

In the traditional IAT, two target categories were presented, one consisting of 5 alcoholic drinks (label 'alcohol') and the other of 5 soft drinks (label 'soda'). The alcohol and soda categories were matched on familiarity $(M=5.20, \mathrm{SD}=1.64$, and $M=5.67, \mathrm{SD}=1.35$, respectively; $1=$ completely unfamiliar, $7=$ very familiar $)$, valence $(M=4.08, \mathrm{SD}=1.15$, and $M=4.43, \mathrm{SD}=.96$, respectively; $1=$ extremely negative, $7=$ extremely positive), arousal $(M=3.84, \mathrm{SD}=.97$, and $M=4.25, \mathrm{SD}=1.02$, respectively; $1=$ extremely passive, $7=$ extremely active), and number of syllables. Further, in the traditional IAT, the two attribute categories consisted of 5 positive (label 'pleasant'; $M=6.45, \mathrm{SD}=.61$ ), and 5 negative (label 'unpleasant'; $M=1.43, \mathrm{SD}=.56)$ stimuli. The attribute categories were matched, as closely as possible, on familiarity $(M=6.21, \mathrm{SD}=.88$, and $M=5.29, \mathrm{SD}=1.64$, respectively), arousal $(M=4.22$, $\mathrm{SD}=1.10$, and $M=3.84, \mathrm{SD}=.84$, respectively), and number of syllables. All stimuli that were

\footnotetext{
1 A standard alcoholic drink in Holland contains less alcohol than a standard English or American alcoholic drink: 10 vs. 14 g, respectively.
} 
presented in the traditional IAT are listed in the Appendix. For the personalized IAT, all stimuli were selected through a questionnaire completed by the participants before the onset of the study. On this questionnaire, participants listed their five most favorite alcoholic drinks as well as their five most favorite sodas, which were subsequently used as stimuli for the alcohol and soda target categories, respectively. Also, participants listed five things they associated with positive feelings, and five things they associated with negative feelings. These positive and negative stimuli were then used as stimuli for the positive and negative attribute categories, respectively. The target categories were labeled 'my drink' (alcohol) and 'my soda' (soda), while the attribute categories were labeled 'I like' (positive) and 'I dislike' (negative).

The traditional IAT and the personalized IAT were programmed in ERTS 3.18 (Beringer, 1996) and consisted of 5 blocks. Participants first practiced the target discrimination with a right and a left response key (e.g., 'alcohol' vs. 'soda'). All target stimuli were presented twice, resulting in 20 target practice trials. In the second block, participants received 20 trials during which they practiced the classification of the attribute dimension (e.g., 'unpleasant' vs. 'pleasant' or 'I dislike' vs. 'I like') with the same response keys. Again, all attribute stimuli were presented twice. The third block was the first combination block during which both target and attribute stimuli were presented twice, resulting in 40 trials (e.g., 'alcohol' + 'unpleasant'/'I dislike' vs. 'soda'+ 'pleasant'/'I like'). Next, participants received 20 trials in which they practiced the reversed attribute discrimination (e.g., 'pleasant' vs. 'unpleasant' or 'I like' vs. 'I dislike'), followed by the reversed combination block, which consisted of 40 trials (e.g., 'alcohol' + 'pleasant'/'I like' vs. 'soda' + 'unpleasant'/‘I dislike').

Target and attribute stimuli were always presented randomly in alternating order. Stimuli were presented in the middle of the computer screen, in black against a grey background. Instructions were presented before each task. During the task, the labels of the categories assigned to the left and right response key were presented in the corresponding upper corner of the computer screen. Stimuli remained on screen until a response was given. The intertrialinterval was $250 \mathrm{~ms}$. During the traditional IAT, feedback was presented in red beneath the stimuli after an incorrect response ('wrong'), and when responses were too fast ( $<300 \mathrm{~ms}$; 'too fast') or too slow ( $>3000 \mathrm{~ms}$; 'too slow'). No feedback was presented during the personalized IAT.

\subsubsection{Explicit expectancies and attitudes}

Explicit alcohol-related expectancies were measured with an expectancy questionnaire that consisted of 6 positive expectancy items $(\alpha=.83)$, and 6 negative expectancy items $(\alpha=.84)$. Each item asked participants to indicate on a $100 \mathrm{~mm}$ Visual Analogue Scale (VAS) how much they agreed ( $0=$ completely disagree, $100=$ completely agree) with the statement: "After drinking alcohol, I feel..." which was completed with the following words: active, lively, impulsive, spontaneous, talkative, and sociable for the positive expectancy items, miserable, sad, lonely, unhappy, unpleasant, and gloomy for the negative expectancy items. Explicit attitudes toward alcohol were assessed with an attitude questionnaire which consisted of 2 semantic differentials: Participants indicated on a $100 \mathrm{~mm}$ VAS how much they considered drinking alcohol to be unpleasant-pleasant, boring-fun $(\alpha=.92)$.

\subsection{Procedure}

First, participants filled out an informed consent form. Participants then performed the traditional IAT and the personalized IAT in balanced order. Also, the response assignment of the target categories, as well 
Table 1

Correlations of both the traditional IAT and the personalized IAT with explicit alcohol-related expectancies and attitudes, alcohol use, and alcohol-related problems

\begin{tabular}{|c|c|c|c|c|c|}
\hline \multirow[t]{2}{*}{ Variable } & \multicolumn{2}{|l|}{ IAT } & \multicolumn{2}{|c|}{ Expectancies } & \multirow[t]{2}{*}{ Attitude } \\
\hline & Traditional & Personalized & Positive & Negative & \\
\hline Personalized IAT & $.39 * *$ & - & - & - & - \\
\hline Positive expectancies & -19 & .09 & - & - & - \\
\hline Negative expectancies & -.15 & -.11 & -.22 & - & - \\
\hline Attitude toward alcohol & -.10 & -.17 & $.47 * *$ & $-.55 * *$ & - \\
\hline Alcohol use & $-.37 *$ & $-.31 *$ & $.33 *$ & -.17 & $.48 * *$ \\
\hline Alcohol-related problems & -.23 & -.24 & $.44 *$ & -.17 & $.46^{* *}$ \\
\hline
\end{tabular}

Note. $* *=$ Correlation is significant at the 0.01 level $(2$-tailed), $*=$ Correlation is significant at the 0.05 level $(2$-tailed).

as the order of the combination tasks were balanced across participants and remained the same during both the traditional IAT and the personalized IAT. Next, participants filled out the alcohol expectancy questionnaire, the alcohol attitude questionnaire, the alcohol use questionnaire, the AUDIT and the RAPI. Finally, participants rated all stimuli on familiarity, valence and arousal.

\section{Results}

\subsection{Implicit alcohol associations}

IAT effects were calculated with both the D600 scoring algorithm (Greenwald, Nosek, \& Banaji, 2003) and with the conventional log measure (Greenwald et al., 1998) because the two algorithms can show markedly different results (e.g., Wiers et al., 2005) and because there is no consensus yet on which measure is optimal (e.g., Greenwald, Nosek, Banaji, \& Klauer, 2005 vs. Rothermund, Wentura, \& De Houwer, 2005). Therefore, results with the D600 measure are reported and where differences were found with the conventional measure, these will be indicated. First, trials with response latencies below $300 \mathrm{~ms}$ or above $3000 \mathrm{~ms}$ were recoded to $300 \mathrm{~ms}$ and $3000 \mathrm{~ms}$, respectively. Mean response latencies were calculated for the two combination tasks separately for the traditional IAT and the personalized IAT. Next, the conventional measure was calculated as the difference between these two log-transformed means so that higher IAT scores indicate faster performance for the compatible response assignment ('alcohol' + 'unpleasant'/'I dislike' vs. 'soda'+ 'pleasant'/'I like') than for the incompatible response assignment ('alcohol' + 'pleasant'/'I like' vs. 'soda' + 'unpleasant'/'I dislike'). The D600 measure was calculated in the same direction. Further, following the formula presented by Greenwald et al., practice blocks were included, error penalties $(600 \mathrm{~ms})$ were given, and results were standardized at the level of the participant.

Preparatory analyses revealed no influential outliers on IAT data. Results revealed a significant difference between the traditional IAT and the personalized IAT, $t(45)=2.20, p=.033^{2}$. Consistent with

\footnotetext{
${ }^{2}$ When results were analyzed using the conventional IAT effect measure, the difference between the traditional IAT and the personalized IAT was borderline significant, $t(45)=1.70, p=.097$, but in the same direction.
} 
Table 2

Summary of hierarchical regression analysis for the prediction of alcohol use by alcohol-related expectancies and attitudes (step 1), and IAT effect scores of the traditional IAT and the personalized IAT (step 2 and 3)

\begin{tabular}{|c|c|c|c|c|c|c|c|}
\hline Step & Variable & $B$ & SE $B$ & $\beta$ & $\mathrm{SE} \beta$ & $t$ & $p$ \\
\hline \multirow[t]{3}{*}{1} & Positive alcohol expectancies & .01 & .01 & .13 & .15 & .87 & .391 \\
\hline & Negative alcohol expectancies & .01 & .01 & .13 & .16 & .78 & .439 \\
\hline & Attitude toward alcohol & .02 & .01 & .48 & .18 & 2.74 & .009 \\
\hline \multirow[t]{4}{*}{2} & Positive alcohol expectancies & .01 & .01 & .08 & .15 & .56 & .581 \\
\hline & Negative alcohol expectancies & .00 & .01 & .04 & .16 & .24 & .811 \\
\hline & Attitude toward alcohol & .02 & .01 & .43 & .17 & 2.51 & .016 \\
\hline & Traditional IAT & -.46 & .20 & -.30 & .13 & -2.26 & .029 \\
\hline \multirow[t]{4}{*}{2} & Positive alcohol expectancies & .01 & .01 & .19 & .15 & 1.27 & .212 \\
\hline & Negative alcohol expectancies & .00 & .01 & .05 & .16 & .30 & .770 \\
\hline & Attitude toward alcohol & .02 & .01 & .37 & .18 & 2.02 & .050 \\
\hline & Personalized IAT & -.33 & .18 & -.26 & .14 & -1.88 & .068 \\
\hline \multirow[t]{5}{*}{3} & Positive alcohol expectancies & .01 & .01 & .13 & .15 & .85 & .399 \\
\hline & Negative alcohol expectancies & .00 & .01 & .01 & .16 & .04 & .969 \\
\hline & Attitude toward alcohol & .02 & .01 & .37 & .18 & 2.05 & .047 \\
\hline & Traditional IAT & -.36 & .22 & -.24 & .14 & -1.66 & .104 \\
\hline & Personalized IAT & -.21 & .19 & -.17 & .15 & -1.13 & .265 \\
\hline
\end{tabular}

Note. IAT effects for both the traditional IAT and the personalized IAT were scored so that positive values indicate faster responses if the alcohol category was assigned to the same response as the negative attribute category (and soda to the same response as the positive attribute category). $F(3,42)=4.74, p=.006, R^{2}=.25$, for step 1 ; When the traditional IAT was entered in step 2 and the personalized IAT in step $3, F(1,41)=5.12, p=.029, R_{\text {change }}^{2}=.08$, for step 2 and $F(1,40)=1.28, p=.265, R_{\text {change }}^{2}=.02$, for step 3 . Final model (step 2): $R^{2}=.34, R_{\text {adjusted }}^{2} .27, F(4,41)=5.18, p=.002$. When the personalized IAT was entered in step 2 and the traditional IAT in step $3, F(1,41)=3.52, p=.068, R_{\text {change }}^{2} .06$, for step 2 and $F(1,40)=2.76, p=.104, R_{\text {change }}^{2}=.04$, for step 3 . Final model ( $\operatorname{step} 2): R^{2}=.31, R_{\text {adjusted }}^{2} .25, F(4,41)=4.65, p=.003$.

previous findings, the IAT effect in the traditional IAT was significant, $t(45)=6.61, p<.001$, indicating that participants were faster when alcohol shared a response with the negative attribute category than when alcohol was paired with the positive attribute category. In the personalized IAT, the IAT effect was also significant, $t(45)=3.26, p=.002$, and in the same direction as the IAT effect in the traditional IAT. Hence, results demonstrate that participants associated alcohol more with negative than with positive in the traditional IAT, and to a lesser extent also in the personalized IAT.

\subsection{Explicit alcohol-related expectancies and attitudes}

Mean scores were calculated separately for the positive and negative expectancy items. Results showed that participants agreed significantly more with positive expectancies $(M=65.02, \mathrm{SD}=16.80)$ than with negative expectancies $(M=18.70, \mathrm{SD}=12.41), t(45)=13.66, p<.001$. Further, mean attitude scores were also calculated from the alcohol attitude questionnaire. Results showed that participants' mean attitude score $(M=72.25, \mathrm{SD}=18.44)$ deviated significantly from the midpoint of the scale, $t(45)=8.18, p<.001$, indicating that participants had a favorable attitude towards alcohol. We then examined the relationship of the traditional IAT and the personalized IAT with alcohol-related expectancies and attitudes (see Table 1). None of the correlations between the two IAT versions and explicit alcohol-related cognitions reached conventional levels of significance. 
Table 3

Summary of hierarchical regression analysis for the prediction of alcohol-related problems by alcohol-related expectancies and attitudes (step 1), and IAT effect scores of the traditional IAT and the personalized IAT (step 2 and 3)

\begin{tabular}{|c|c|c|c|c|c|c|c|}
\hline Step & Variable & $B$ & SE $B$ & $\beta$ & $\mathrm{SE} \beta$ & $t$ & $p$ \\
\hline \multirow[t]{3}{*}{1} & Positive alcohol expectancies & .02 & .01 & .28 & .15 & 1.88 & .068 \\
\hline & Negative alcohol expectancies & .01 & .01 & .10 & .16 & .61 & .548 \\
\hline & Attitude toward alcohol & .02 & .01 & .38 & .17 & 2.18 & .035 \\
\hline \multirow[t]{4}{*}{2} & Positive alcohol expectancies & .01 & .01 & .26 & .15 & 1.70 & .096 \\
\hline & Negative alcohol expectancies & .00 & .01 & .06 & .16 & .345 & .732 \\
\hline & Attitude toward alcohol & .02 & .01 & .35 & .18 & 2.01 & .051 \\
\hline & Traditional IAT & -.18 & .18 & -.14 & .14 & -.99 & .328 \\
\hline \multirow[t]{4}{*}{2} & Positive alcohol expectancies & .02 & .01 & .33 & .15 & 2.20 & .034 \\
\hline & Negative alcohol expectancies & .00 & .01 & .03 & .16 & .19 & .851 \\
\hline & Attitude toward alcohol & .01 & .01 & .28 & .18 & 1.56 & .128 \\
\hline & Personalized IAT & -.24 & .15 & -.22 & .14 & -1.58 & .122 \\
\hline \multirow[t]{5}{*}{3} & Positive alcohol expectancies & .02 & .01 & .31 & .16 & 2.01 & .051 \\
\hline & Negative alcohol expectancies & .00 & .01 & .02 & .16 & .12 & .907 \\
\hline & Attitude toward alcohol & .01 & .01 & .28 & .18 & 1.54 & .133 \\
\hline & Traditional IAT & -.09 & .20 & -.06 & .15 & -.43 & .670 \\
\hline & Personalized IAT & -.22 & .17 & -.19 & .15 & -1.28 & .21 \\
\hline
\end{tabular}

Note. IAT effects for both the traditional IAT and the personalized IAT were scored so that positive values indicate faster responses if the alcohol category was assigned to the same response as the negative attribute category (and soda to the same response as the positive attribute category). $F(3,42)=5.40, p=.003, R^{2}=.28$, for step 1 ; When the traditional IAT was entered in step 2 and the personalized IAT in step $3, F(1,41)=.98, p=.328, R_{\text {change }}^{2}=.02$, for step 2 and $F(1,40)=1.64, p=.208, R_{\text {change }}^{2}=.03$, for step 3 . When the personalized IAT was entered in step 2 and the traditional IAT in step $3, F(1,41)=2.50, p=.122, R_{\text {change }}^{2}=.04$, for step 2 and $F(1,40)=.18, p=.670, R_{\text {change }}^{2}=.00$, for step 3. Final model (step 1$): R^{2}=.28, R_{\text {adjusted }}^{2} .23, F(3,42)=5.40, p=.003$.

\subsection{Relationship of implicit associations to alcohol use and related problems}

Alcohol consumption during the past week and average weekly alcohol consumption were estimated from the alcohol use questionnaire. An estimate of alcohol use was then calculated as the mean of average alcohol consumption during the past week and average weekly alcohol consumption. Further, average alcohol use during the past week and average alcohol use were first log-transformed in order to obtain a normal distribution for the alcohol use estimate. An estimate for mean alcohol-related problems was computed as the mean of the $z$-transformed RAPI and AUDIT sum scores. To obtain a normal distribution, RAPI and AUDIT sum scores were first log-transformed. These two estimates were significantly correlated, $r=.74, p<.001$, indicating that participants with increased levels of alcohol consumption also experienced more alcohol-related problems. As can be seen in Table 1, the traditional IAT and the personalized IAT both correlated significantly with alcohol use.

Next, we tested the predictive validity of the explicit measures and the incremental validity of the traditional IAT and the personalized IAT using hierarchical regression analysis. ${ }^{3}$ Regression analyses were performed separately for the prediction of alcohol use and alcohol-related problems. Explicit alcohol-

\footnotetext{
${ }^{3}$ Statistical power in the reported hierarchical regression analyses was sufficient (above .85). Further, in our hierarchical regression models, VIF values were well below 10 while tolerance statistics were well above .2, indicating that there was no collinearity in the data.
} 
related expectancies and attitudes toward alcohol were always entered in step 1. In order to examine the incremental validity of both the traditional IAT and the personalized IAT, regression analyses were performed twice, once with the traditional IAT entered in step 2 and the personalized IAT entered in step 3, and once with the two IAT versions entered in the reversed order. The hierarchical regression analysis predicting alcohol use is shown in Table 2. In step 1 of the regression analysis, attitudes toward alcohol significantly predicted alcohol use. When the traditional IAT was entered in step 2, results showed that the traditional IAT significantly predicted alcohol use above explicit attitudes toward alcohol. However, when the personalized IAT was then entered in step 3, the variance explained was not significantly increased. When the personalized IAT was entered in step 2 and the traditional IAT in step 3, results showed that the personalized IAT predicted alcohol use at borderline significance above explicit attitudes toward alcohol in step 2 while entering the traditional IAT in step 3 did not increase the variance explained. ${ }^{4}$ The hierarchical regression analysis for the prediction of alcohol-related problems is shown in Table 3. In step 1, explicit positive expectancies predicted alcohol-related problems at borderline significance, while explicit attitudes toward alcohol significantly predicted alcohol-related problems. Neither the traditional IAT nor the personalized IAT significantly predicted alcohol-related problems above explicit alcoholrelated expectancies and attitudes. ${ }^{5}$

\section{Discussion}

Alcohol-IAT studies have repeatedly demonstrated the counterintuitive finding that drinkers display implicit negative attitudes toward alcohol that do not have a strong impact on alcohol-related behavior (e.g., De Houwer et al., 2004; Wiers et al., 2002, 2005). Here, it was examined whether support for implicit negative attitudes toward alcohol might be due to contamination of IAT effects by negative extrapersonal information about drinking alcohol that is attitude-irrelevant. To test this hypothesis, we compared a traditional IAT with a personalized IAT (cf. Olson \& Fazio, 2004) that presented individualized stimuli that were selected by participants themselves instead of standard stimuli (cf. Fadardi et al., 2006). This was done because standard target (and attribute) concepts do not necessarily evoke the same attitudes in all participants. Results with the standard IAT yielded support for implicit negative attitudes toward alcohol, replicating previous findings.

As expected, support for implicit negative attitudes toward alcohol was significantly reduced in the personalized IAT. Contrary to the hypothesis, however, we found no support for implicit positive attitudes toward alcohol with the personalized IAT. Instead, the personalized IAT demonstrated markedly reduced but still significant IAT effects indicative of implicit negative attitudes toward alcohol. Further, both the traditional and the personalized IAT predicted drinking behavior in such a way that stronger implicit positive attitudes toward alcohol (or weaker negative attitudes toward alcohol) were related to an increase

\footnotetext{
4 When IAT effects were calculated using the conventional IAT effect measure, entering the personalized IAT in step 2 of the hierarchical regression analysis for the prediction of alcohol use significantly increased the variance explained, $F(1,41)=5.88$, $p=.020, R_{\text {change }}^{2}=.09$, and the personalized IAT significantly predicted alcohol use above explicit attitudes toward alcohol, $\beta=-.34$, $p=.020$. Entering the traditional IAT in step 3 did not increase the variance explained, $F(1,40)=1.41, p=.242$.

5 When IAT effects were calculated using the conventional IAT effect measure, entering the personalized IAT in step 2 of the hierarchical regression analysis for the prediction of alcohol-related problems borderline significantly increased the variance explained, $F(1,41)=3.50, p=.069, R_{\text {change }}^{2}=.06$, and the personalized IAT predicted alcohol-related problems at borderline significance above explicit attitudes toward alcohol, $\beta=-.26, p=.069$. Entering the traditional IAT in step 3 did not increase the variance explained, $F(1,40)=.06, p=.812$.
} 
in alcohol consumption. Moreover, the traditional IAT and the personalized IAT predicted alcohol use above explicit alcohol-related cognitions, demonstrating that these implicit measures explain additional variance in drinking behavior that is not captured by explicit measures. From a broader perspective these results, thus, indicate that both explicit and implicit cognitive processes steer drinking behavior, a notion that is consistent with contemporary dual-process models of addiction (see Wiers \& Stacy, 2006a,b).

Consistent with the extrapersonal contamination hypothesis, evidence for implicit negative attitudes toward alcohol was significantly reduced in a personalized IAT that presented individualized stimuli compared to a standard IAT. However, in contrast to the hypothesis, the personalized IAT did not show evidence for implicit positive attitudes toward alcohol. Houben and Wiers (in press), on the other hand, demonstrated implicit positive attitudes toward alcohol in a personalized IAT that presented standard stimuli without reference to normative feedback. Thus, these results suggest that the personalized IAT used in the present study eliminated extrapersonal contamination to a lesser extent than the personalized IAT used by Houben and Wiers (in press). Possibly, the individualized attribute stimuli selected by participants in the present study were in fact normatively associated with valence (e.g., love, peace, war, weapons). Hence, a personalized IAT that presents standard stimuli could be more effective in reducing extrapersonal contamination than an individualized personalized IAT because it allows for more controlled selection of stimuli that are not normatively associated with valence. Nonetheless Han, Olson, and Fazio (2006) recently demonstrated that primarily the category labels in the traditional IAT cause vulnerability to extrapersonal contamination and that personalizing the labels in the IAT is sufficient to reduce the impact of extrapersonal associations.

Alternatively, the difference in results with the personalized IAT between the present study and the study by Houben and Wiers (in press) could be due to differences in the samples of participants. On average, participants in the study by Houben and Wiers (in press) drank 25 alcoholic consumptions per week whereas in the present study, participants on average consumed less than 16 alcoholic drinks a week. Hence, if implicit positive attitudes towards alcohol are stronger for participants with increased levels of alcohol consumption, as suggested by the findings of Houben and Wiers (in press) as well as the present findings, the lower alcohol consumption of participants in the present study compared to participants in the Houben and Wiers (in press) study can explain why participants in the present study on average demonstrated implicit negative attitudes toward alcohol rather than implicit positive attitudes toward alcohol.

Further, the present findings indicate that the predictive validity of the alcohol-IAT used by Wiers et al. (2002, 2005) as well as De Houwer et al. (2004) might have been decreased due to extrapersonal contamination. In line with this conclusion, Houben and Wiers (2006) as well as Houben, Rothermund, and Wiers (submitted for publication) showed that effects in the alcohol-IAT at least partly reflect general recoding processes rather than or in addition to implicit alcohol attitudes. Together, these results suggest that effects in the alcohol-IAT at least to some extent reflect recoding influences, including extrapersonal contamination, in addition to implicit attitudes toward alcohol which can decrease the validity of the task as a measure of implicit alcohol attitudes. Moreover, the present findings are consistent with recent studies that found support for a role of implicit attitudes toward alcohol in alcohol use and abuse with a slight modification of the IAT procedure. When implicit alcohol associations were tested in a unipolar format (e.g., positive vs. neutral and negative vs. neutral) rather than in a bipolar format (e.g., positive vs. negative) so that implicit positive attitudes and implicit negative attitudes could be assessed separately, evidence was found for implicit positive attitudes toward alcohol in addition to strong implicit negative attitudes toward alcohol (Houben \& Wiers, 2006; Jajodia \& Earleywine, 2003). Importantly, implicit 
positive attitudes toward alcohol were at least moderately related to alcohol use while implicit negative attitudes toward alcohol did not show a relationship to alcohol-related behavior (Houben \& Wiers, 2006; Jajodia \& Earleywine, 2003). Hence, these findings suggest that, in the alcohol-IAT, strong implicit negative attitudes toward alcohol, at least to some extent, reflect recoding processes and/or extrapersonal contamination typically overshadow implicit positive attitudes toward alcohol that steer drinking behavior.

Finally, it should be noted that, in the alcohol-IAT, negative implicit attitudes toward alcohol could also be triggered by the choice of the contrasting target concept soda, which is often used in alcoholIATs. Recent studies using a different task than the IAT, namely varieties of the Extrinsic Affective Simon Task (EAST, De Houwer, 2003) that can be used to assess implicit attitudes toward single target concepts, demonstrated positive rather than negative implicit attitudes toward alcohol that were related to alcohol consumption (De Houwer \& De Bruycker, 2007) or indicated implicit ambivalent attitudes toward alcohol that showed a positive relation to alcohol-related behavior (de Jong, Wiers, van de Braak, \& Huijding, 2007). In addition, Houben and Wiers (submitted for publication-a) also recently demonstrated both implicit positive attitudes toward alcohol as well as implicit negative alcohol attitudes with unipolar Single Target IATs (ST-IAT; Karpinski \& Steinman, 2006; Wigboldus, Holland, \& van Knippenberg, 2006) that assessed single implicit attitudes toward alcohol without a contrast category. In contrast, unipolar IATs that assessed implicit alcohol attitudes relative to soda yielded only negative, but no positive, implicit attitudes toward alcohol. These results, thus, show that the target category which is used as a contrast to the alcohol category can influence the overall size of IAT effects.

In sum, consistent across studies that have examined implicit attitudes toward alcohol using variations of the IAT and the EAST, it was demonstrated that implicit positive attitudes toward alcohol are an important determinant of alcohol use and abuse (present study; De Houwer \& De Bruycker, 2007; de Jong et al., 2007; Houben \& Wiers, in press, 2006, submitted for publication-a,b; Jajodia \& Earleywine, 2003). Implicit negative attitudes toward alcohol, in contrast, are unrelated to drinking behavior and are more likely a result of extrapersonal contamination or more general recoding influences, as well as procedural limitations of the IAT procedure (such as the necessity to include a contrast category). Importantly, these results demonstrate that, in addition to implicit appetitive associations (i.e., implicit arousal associations, implicit approach tendencies), implicit attitudes also play an important role in drinking behavior.

\section{Acknowledgement}

Both authors are funded by "VIDI" grant 452.02.005 from the Dutch National Science Foundation (N.W.O.) awarded to the second author.

\section{Appendix A}

\section{Target Stimuli in the Traditional IAT}

Alcohol: beer, wine, whisky, drink, brandy

Soda: Fanta, Coca Cola, Sprite, sinas (lemonade), ice-tea

\section{Attribute Stimuli in the Traditional IAT}

Pleasant: love, sunshine, warmth, peace, hug

Unpleasant: sorrow, war, depression, pain, disease 


\section{References}

Bechara, A., Noel, X., \& Crone, E. A. (2006). Loss of willpower: Abnormal neural mechanisms of impulse control and decision making in addiction. In R. W. Wiers \& A.W. Stacy (Eds.), Handbook of implicit cognition and addiction (pp. 215-232). Thousand Oaks, CA: SAGE Publishers.

Beringer, J. (1996). Experimental Run Time System (ERTS), Version 3.18. Frankfurt, Germany: BeriSoft.

De Houwer, J. (2003). The extrinsic affective simon task. Experimental Psychology, 50, 77-85.

De Houwer, J., Crombez, G., Koster, E. H. W., \& De Beul, N. (2004). Implicit alcohol-related cognitions in a clinical sample of heavy drinkers. Journal of Behavior Therapy and Experimental Psychiatry, 35, 275-286.

De Houwer, J., \& De Bruycker, E. (2007). The identification-EAST as a valid measure of implicit attitudes toward alcohol-related stimuli. Journal of Behavior Therapy and Experimental Psychiatry, 38, 133-143.

de Jong, P. J., Wiers, R. W., van de Braak, M., \& Huijding, J. (2007). Using the Extrinsic Affective Simon Test as a measure of implicit attitudes toward alcohol: Relationship with drinking behavior and alcohol problems. Addictive Behaviors, 32, 881-887.

Deutsch, R., \& Strack, F. (2006). Reflective and impulsive determinants of addictive behavior. In R. W. Wiers \& A.W. Stacy (Eds.), Handbook of implicit cognition and addiction (pp. 45-57). Thousand Oaks, CA: SAGE Publishers.

Evans, J. S. B. T., \& Coventry, K. (2006). A dual process approach to behavioural addiction: The case of gambling. In R. W. Wiers \& A.W. Stacy (Eds.), Handbook of implicit cognition and addiction (pp. 29-43). Thousand Oaks, CA: SAGE Publishers.

Fadardi, J. S., Cox, W. M., \& Klinger, E. (2006). Individualized versus general measures of implicit cognition. In R. W. Wiers \& A.W. Stacy (Eds.), Handbook of implicit cognition and addiction. Thousand Oaks, CA: SAGE Publishers.

Greenwald, A. G., McGhee, D. E., \& Schwartz, J. L. K. (1998). Measuring individual differences in implicit cognition: The implicit association test. Journal of Personality and Social Psychology, 74, 1464-1480.

Greenwald, A. G., Nosek, B. A., \& Banaji, M. R. (2003). Understanding and using the implicit association test: 1. An improved scoring algorithm. Journal of Personality and Social Psychology, 85, 197-216.

Greenwald, A. G., Nosek, B. A., Banaji, M. R., \& Klauer, K. C. (2005). Validity of the salience asymmetry interpretation of the IAT: Comment on Rothermund and Wentura (2004). Journal Of Experimental Psychology: General, 134, $420-425$.

Han, H. A., Olson, M. A., \& Fazio, R. H. (2006). The influence of experimentally-created extrapersonal associations on the Implicit Association Test. Journal of Experimental Social Psychology, 42, 259-272.

Houben, K., Rothermund, K., \& Wiers, R. W. (submitted for publication). Eliminating recoding in the Alcohol-IAT: An application of the IAT-RF. Manuscript submitted for publication.

Houben, K., \& Wiers, R. W. (in press). Are Drinkers Implicitly Positive about Drinking Alcohol? Personalizing the Alcohol-IAT to Reduce Negative Extrapersonal Contamination. Alcohol and Alcoholism.

Houben, K., \& Wiers, R. W. (2006). Assessing implicit alcohol associations with the implicit association test: Fact or artifact? Addictive Behaviors, 31, 1346-1362.

Houben, K., \& Wiers, R. W. (submitted for publication). Implicit positive alcohol attitudes as determinants of alcohol consumption: Beyond the soda contrast in the IAT. Manuscript submitted for publication.

Houben, K., \& Wiers, R. W. (submitted for publication). Single-target implicit preferences for beer as determinants of consumption. Manuscript submitted for publication.

Jajodia, A., \& Earleywine, M. (2003). Measuring alcohol expectancies with the implicit association test. Psychology of Addictive Behaviors, 17, 126-133.

Karpinski, A., \& Hilton, J. L. (2001). Attitudes and the implicit association test. Journal of Personality and Social Psychology, $81,774-788$.

Karpinski, A., \& Steinman, R. B. (2006). The single-category implicit association test as a measure of implicit social cognition. Journal of Personality and Social Psychology, 91, 16-32.

Olson, M. A., \& Fazio, R. H. (2004). Reducing the influence of extra-personal associations on the implicit association test: Personalizing the IAT. Journal of Personality and Social Psychology, 86, 653-667.

Palfai, T. P., \& Ostafin, B. D. (2003). Alcohol-related motivational tendencies in hazardous drinkers: Assessing implicit response tendencies using the modified-IAT. Behavior Research and Therapy, 41, 1149-1162. 
Robinson, T. E., \& Berridge, K. C. (1993). The neural basis of drug craving: An incentive-sensitization theory of addiction. Brain Research Reviews, 18, 247-291.

Rothermund, K., Wentura, D., \& De Houwer, J. (2005). Validity of the salience asymmetry account of the IAT: Reply to Greenwald, Nosek, Banaji, and Klauer (2005). Journal of Experimental Psychology: General, 134, 426-430.

Saunders, J. B., Aasland, O. G., Babor, T. F., De la Fuente, J. R., \& Grant, M. (1993). Development of the Alcohol use Disorders Identification Test (AUDIT): WHO collaborative project on early detection of persons with harmful alcohol consumption. Addiction, 88, 791-804.

Sobell, L. C., \& Sobell, M. B. (1990). Self-report issues in alcohol abuse: State of the art and future directions. Behavioral Assessment, 12, 77-90.

White, H. R., \& Labouvie, E. W. (1989). Towards the assessment of adolescent problem drinking. Journal of Studies on Alcohol, 50, 30-37.

White, H.R., \& Labouvie, E. W. (2000). Longitudinal trends in problem drinking as measured by the Rutgers Alcohol Problem Index. Paper presented at the 23rd Annual Scientific Meeting of the Research Society on Alcoholism. Denver, CO.

Wiers, R. W., Hoogeveen, K. -J., Sergeant, J. A., \& Gunning, W. B. (1997). High- and low-dose alcohol-related expectancies and the differential associations with drinking in male and female adolescents and young adults. Addiction, 92, 871-888.

Wiers, R. W., \& Stacy, A. W. (Eds.). (2006). Handbook of implicit cognition and addiction Thousand Oaks, CA: SAGE Publishers.

Wiers, R. W., \& Stacy, A. W. (2006b). Implicit cognition and addiction. Current Directions in Psychological Science, 15, 292-296.

Wiers, R. W., van de Luitgaarden, J., van den Wildenberg, E., \& Smulders, F. T. Y. (2005). Challenging implicit and explicit alcohol-related cognitions in young heavy drinkers. Addiction, 100, 806-819.

Wiers, R. W., Van Woerden, N., Smulders, F. T. Y., \& de Jong, P. J. (2002). Implicit and explicit alcohol-related cognitions in heavy and light drinkers. Journal of Abnormal Psychology, 111, 648-658.

Wigboldus, D. H. J., Holland, R. W., \& van Knippenberg, A. (2006). Single target implicit associations. Unpublished Manuscript. 